\title{
Value of somatosensory evoked potentials in saphenous entrapment neuropathy
}

\author{
S Tranier, A Durey, B Chevallier, F Liot
}

\begin{abstract}
Neuralgia of the saphenous nerve (SN) is a rare clinical syndrome simulating a vascular disorder of the lower extremities. In four cases, the presenting complaint was persistent pain on the medial aspect of the knee. Examination revealed tenderness over the site of exit of the SN from the femoral canal. Femoral nerve motor conduction, quadriceps H-reflex and EMG of the leg muscles were normal. The sensory nerve action potential of the $\mathrm{SN}$ in the leg was not obtained in some patients, even in the unaffected leg. SEP were therefore preferred for diagnosis and performed at the infrapatellar and descending branches of the right and left $S N$ and recordings from the $\mathrm{Cz}^{\prime}-\mathrm{Fz}$ electrode. Latency and amplitude differences were evaluated and compared with a control group of healthy subjects. An alteration in the SEP from one branch was observed on the painful side. Posterior tibial responses were normal. In one case, pain resolved immediately after neurolysis, confirming SN entrapment above the femoral canal, before its division. Pain resolved in two other cases and persisted in the last after medical treatment. SEP studies are valuable in the diagnosis of an isolated lesion of the SN.
\end{abstract}

Primary entrapment of the saphenous nerve (SN) is very uncommon, ${ }^{1}$ but scar entrapment may occur often after knee surgery, ${ }^{23}$ and has been the subject of some recent studies. ${ }^{4-6}$ It is commonly taken for a radicular (L3-L4), vascular, muscular or articular disorder and clinical diagnosis is difficult. In many diseases of peripheral nerves, electromyography (EMG) may be adequate for diagnosis, especially if the sensory nerve action potential (SNAP) can be recorded. Unfortunately, SNAP cannot be recorded in some $\mathrm{SN}$ entrapment patients, even in the unaffected leg. This method is therefore inconclusive.

The clinical application of somatosensory evoked potentials (SEP) has helped resolve the diagnosis of both central and peripheral nerve diseases. In recent years, SEP techniques have been used to study the SN.

\section{Patients and methods}

1) Four patients with $S N$ entrapment were observed ( 2 males, 2 females, mean (SD) age $37.5(13 \cdot 2)$ years, range 21 to 52 , mean (SD) height $1.70(0.09)$ metres). The clinical,radiological and electrophysiological data of the four patients are shown in table 1.

2) Twelve normal subjects ( 9 males, 3 females, mean (SD) age $34.3(9.5)$ years, range 21 to 52 , mean (SD) height $1.79(0.06)$ metres) also
Service Central d'Explorations Fonctionnelles, Hôpital Ambroise Paré, Boulogne, France

$S$ Tranier

B Chevallier

F Liot

Service de

Rééducation

Fonctionnnelle,

Hôpital Foch,

Suresnes, France

A Durey

Correspondence to: Dr Tranier, Hôpital Avicenne, Service d'Explorations Fonctionnelles (physiologie), 125 route de Stalingrad, 93009 Bobigny, France

Received 13 February 1991 and in final revised form 22 July 199

Accepted 30 July 199
Table 1 Clinical, radiological and electrophysiological findings in 4 patients with saphenous nerve entrapment.

\begin{tabular}{|c|c|c|c|c|}
\hline Patient (No) & 1 & 2 & 3 & 4 \\
\hline $\begin{array}{l}\text { Age (years) } \\
\text { Sex } \\
\text { Height (metres) }\end{array}$ & $\begin{array}{l}43 \\
F \\
1.63\end{array}$ & $\begin{array}{l}34 \\
M \\
1 \cdot 78\end{array}$ & $\begin{array}{l}21 \\
M \\
1 \cdot 80\end{array}$ & $\begin{array}{l}52 \\
F \\
1.62\end{array}$ \\
\hline $\begin{array}{l}\text { Affected side } \\
\text { Duration of pain (years) } \\
\text { External causes }\end{array}$ & $\begin{array}{l}\mathrm{L} \\
3 \\
0\end{array}$ & $\begin{array}{l}R \\
2 \\
\text { shock knee (football) }\end{array}$ & $\begin{array}{l}R \\
0 \cdot 25 \\
\text { heavy hyper- } \\
\text { extension (knee) }\end{array}$ & $\begin{array}{l}\mathrm{L} \\
>5 \\
\text { Meniscectomy }\end{array}$ \\
\hline Aggravating factors & $\begin{array}{l}\text { jogging, gymnastics, } \\
\text { rubbing of bed linen, } \\
\text { heat, constrained } \\
\text { flexion of knee }\end{array}$ & walks, stairs & $\begin{array}{l}\text { Hyperextension of } \\
\text { knee and thigh }\end{array}$ & walks, stairs \\
\hline $\begin{array}{l}\text { Tinel and local anaesthetic test } \\
\text { Skin P-R test (cellulalgia) } \\
\text { Facilitation tests } \\
\text { Hypo or anaesthesia }\end{array}$ & $\begin{array}{l}+ \\
+ \\
+ \\
-\end{array}$ & $\begin{array}{l}+ \\
+ \\
+ \\
+\end{array}$ & $\begin{array}{l}+ \\
+ \\
+ \\
-\end{array}$ & $\begin{array}{l}+ \\
+ \\
+ \\
+\end{array}$ \\
\hline $\begin{array}{l}\text { X Ray (knee lumbar spine) } \\
\text { Arthroscopy } \\
\text { Meniscography } \\
\text { Echography (muscles) } \\
\text { Arteriography }\end{array}$ & $\begin{array}{l}\mathbf{N} \\
\mathbf{N} \\
\mathbf{N} \\
\mathbf{N}\end{array}$ & $\begin{array}{l}\mathbf{N} \\
\mathbf{N} \\
\mathbf{N} \\
\mathbf{N}\end{array}$ & $\begin{array}{l}\mathbf{N} \\
\mathbf{N}\end{array}$ & $\begin{array}{l}\mathbf{N} \\
\mathbf{N} \\
\mathbf{N}\end{array}$ \\
\hline $\begin{array}{l}\text { Needle EMG } \\
\text { H or } T \text { reflex/rectus femoris }\end{array}$ & $\mathbf{N}$ & $\mathbf{N}$ & $\begin{array}{l}\mathbf{N} \\
\mathbf{N}\end{array}$ & $\begin{array}{l}\mathbf{N} \\
\mathbf{N}\end{array}$ \\
\hline MCV femoral nerve $\mathrm{MCV} \mathrm{m} / \mathrm{s}$ & $68 \cdot 5$ & $83 \cdot 8$ & $72 \cdot 9$ & $80 \cdot 7$ \\
\hline $\begin{array}{l}\text { Saphenous nerve } \\
\text { L SAP }(\mu \mathrm{V}) \\
\text { R SCV }(\mathrm{m} / \mathrm{s}) \\
\text { SAP }(\mu \mathrm{V})\end{array}$ & $\begin{array}{l}0 \\
38 \\
15\end{array}$ & $\frac{0}{0}$ & $\begin{array}{l}0 \\
40 \cdot 2 \\
6 \cdot 5\end{array}$ & $\frac{0}{0}$ \\
\hline
\end{tabular}

$\mathrm{F}=$ female; $M$ = male; $\mathrm{L}=$ left; $R=$ right; + = positive; - negative. Skin $P-R$ test = skin pinching-rolling test; SAP = sensory action potential. MCV or SCV = motor, sensory conduction velocity; $\mathrm{N}=$ normal. 


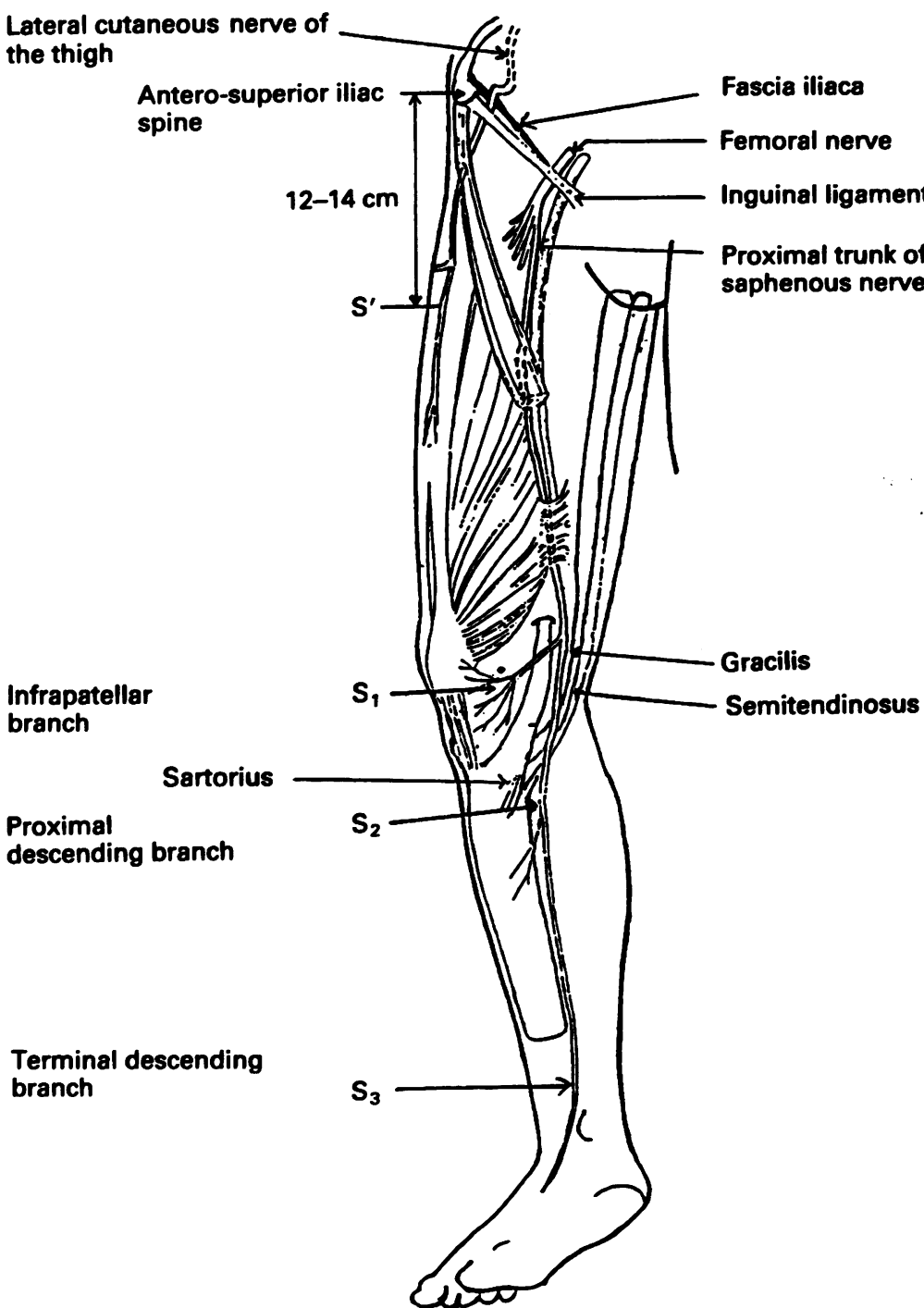

Figure 1 Saphenous nerve and its 3 branches: sites of stimulation to record somatosensory evoked potentials. tendon, just below the medial tibial condyle. The stimulation of these two branches was based on anatomical findings. ${ }^{10} 11$

C) The terminal descending branch (TDB) in the ankle was stimulated two fingers above the medial malleolus just medial to the tibia. ${ }^{78}$

Both legs were stimulated sequentially with bipolar cutaneous electrodes with the cathode positioned proximally. Square pulses $(0.2 \mathrm{~ms})$ of constant current were delivered at a frequency of $3 \mathrm{~Hz}$ and an intensity four times the sensory threshold. The current was adjusted until sensation radiated along the distribution of the PDB and TDB. The posterior tibial nerve (PTN) was also stimulated. The subjects were instructed to lie supine and relax in a quiet room at a temperature of $23-25^{\circ} \mathrm{C}$.

The recordings were made from the active electrode $2 \mathrm{~cm}$ posterior to the vertex of the scalp $\left(\mathrm{Cz}^{\prime}\right)$ with respect to the reference electrode at $\mathrm{Fz}$ (10-20 system). The ground electrode was attached to the thigh (lower third) on the stimulated side. Standard needle electrodes (DANTEC) were used for recording the responses. The amplifier bandpass was $10-500 \mathrm{~Hz}$. The analysis time was $200 \mathrm{~ms}$ and 2 sequential runs of 500 sweeps were averaged to check the constancy of the response. The latencies and amplitudes of the initial negative (upward, $\mathrm{Nl}$ ) and initial positive (downward, P1) peaks were measured.

OTHER INVESTIGATIONS WERE PERFORMED IN THE PATIENTS ONLY

Needle EMG and motor conduction velocity (CV) of the femoral nerve were studied. Sensory CV of the SN was studied in the leg according to the antidromic method of Wainapel et al. ${ }^{12}$ Hoffmann (H) or tendon (T) reflexes of the rectus femoris muscle were measured according to the technique of Guiheneuc. ${ }^{13}$

\section{Results}

SEP IN NORMAL SUBJECTS

The SEP of the SN is a W-shaped wave. The early cortical responses are labelled N1, P1, $\mathrm{N} 2$. The onset is referred to as N1. The results of measurement of $\mathrm{P1}$ are shown in table 2: side-to-side, there was no statistically significant difference in P1 latency. The amplitude of P1 was variable from one subject to another, and even from side-to-side. Nevertheless, Pl was the most reliable response and formed the basis for most of the analysis.

Table 2 SEP after stimulation of 24 different branches of the saphenous nerve (SN) and posterior tibial nerve (PTN) in 12 normal subjects: study of P1 (mean values).

\begin{tabular}{|c|c|c|c|c|}
\hline Nerves & $\begin{array}{l}\text { Latency (ms) } \\
\text { Mean (SD) }\end{array}$ & $\begin{array}{l}\text { Amplitude } \\
\text { peak to peak }(\mu V) \\
\text { Mean }(S D)\end{array}$ & $\begin{array}{l}\text { Side to side } \\
\text { (differences in latency) (ms) } \\
\text { Mean (SD) (range) }\end{array}$ & $\begin{array}{l}\text { Ratios of amplitude } \\
\text { (smallest/largest) } \\
\text { Mean (SD) (range) }\end{array}$ \\
\hline$\overline{\mathbf{S N}}$ & & & \multirow{5}{*}{$\begin{array}{c}0.85(0.18) \\
(0.6-1.2) \\
0.55(0.35) \\
(0.1-1) \\
0.68(0.2) \\
(0.4-1) \\
0.54(0.26) \\
(0.1-0.8)\end{array}$} & \multirow{5}{*}{$\begin{array}{c}0.80(0.10) \\
(0.65-0.92) \\
0.75(0.09) \\
(0.60-0.90) \\
0.79(0.11) \\
(0.65-0.96) \\
0.77(0.05) \\
(0.71-0.88)\end{array}$} \\
\hline IPB & $37 \cdot 7(2 \cdot 95)$ & $1.34(1.03)$ & & \\
\hline PDB & $36 \cdot 37(2 \cdot 66)$ & $1.61(0.87)$ & & \\
\hline TDB & $40.97(2 \cdot 13)$ & $1.43(0.72)$ & & \\
\hline PTN & $38.53(1.9)$ & $2 \cdot 63 \cdot(2 \cdot 17)$ & & \\
\hline
\end{tabular}

IPB = infrapatellar branch; PDB = proximal descending branch; TDB = terminal descending branch. 
Table 3 Data of P1 of SEP from saphenous nerve (SN) stimulation on the affected sides in 4 patients.

\begin{tabular}{|c|c|c|c|c|c|}
\hline \multirow[b]{2}{*}{$S N$} & \multirow{2}{*}{$\begin{array}{l}\text { Control group } \\
\text { (normal values) } \\
\text { Mean (SD) }\end{array}$} & \multicolumn{4}{|c|}{ Number of cases } \\
\hline & & No 1 & No 2 & No 3 & No 4 \\
\hline $\begin{array}{l}\text { IPB } \\
\text { Latency-difference (ms) } \\
\text { Amplitude Ratio (S/L) }\end{array}$ & $\begin{array}{l}0.85(0.10) \\
0.80(0.10)\end{array}$ & $\begin{array}{l}0.70 \\
0.70\end{array}$ & $\begin{array}{l}\text { Absent } \\
\text { Absent }\end{array}$ & $\begin{array}{l}2 \cdot 8 \\
0 \cdot 22\end{array}$ & $\begin{array}{l}5 \cdot 2 \\
0 \cdot 72\end{array}$ \\
\hline $\begin{array}{l}\text { PDB } \\
\text { Latency-difference (ms) } \\
\text { Amplitude Ratio (S/L) }\end{array}$ & $\begin{array}{l}0.55(0.35) \\
0.75(0.09)\end{array}$ & $\begin{array}{l}0.6 \\
0.29\end{array}$ & $\begin{array}{l}\text { Absent } \\
\text { Absent }\end{array}$ & $\begin{array}{l}0.70 \\
0.72\end{array}$ & $\begin{array}{l}3 \cdot 2 \\
0.58\end{array}$ \\
\hline $\begin{array}{l}\text { TDB } \\
\text { Latency-difference (ms) } \\
\text { Amplitude Ratio (S/L) }\end{array}$ & $\begin{array}{l}0.68(0.21) \\
0.79(0.11)\end{array}$ & $\begin{array}{l}3 \cdot 6 \\
0 \cdot 25\end{array}$ & - & $\begin{array}{l}0.60 \\
0.44\end{array}$ & $\begin{array}{l}4.8 \\
0.69\end{array}$ \\
\hline
\end{tabular}

- = not studied; IPB = infrapatellar branch; PDB = proximal descending branch; TDB = terminal descending branch;

$\mathrm{S} / \mathrm{L}=$ smallest/largest.

SEP in patients may be considered abnormal if an interside difference in latency exceeds the mean value by more than 3 standard deviations. Because amplitude is such a variable measure, we considered a response as abnormal only if the ratio of smallest/largest amplitude was less than $\mathbf{0 \cdot 5}$, or if the response was absent unilaterally. ${ }^{7}$ In none of our normal subjects was this ratio of amplitude less than 0.5 in both measurements. Thus each patient served as his/her own control and was also compared with a control group for latency and amplitude criteria.

PATIENTS: CASE REPORTS

The results of SEP from the $S N$ of the affected side are shown in table 3.

CASE 1

In 1988, electrophysiological studies were performed. SEP were normal bilaterally after

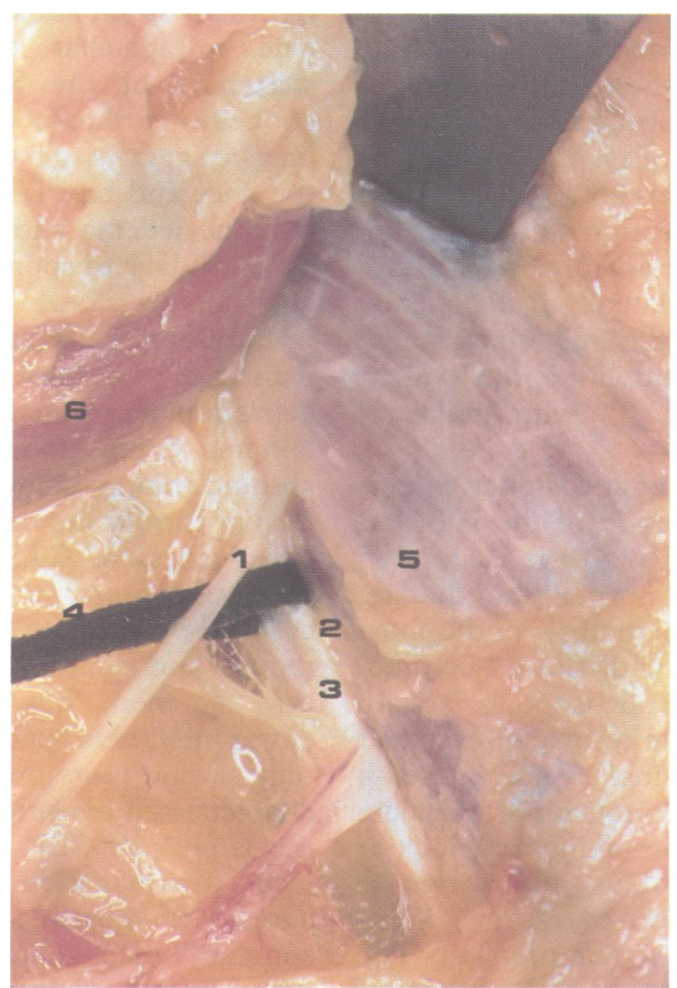

Figure 2 Operative appearance of left saphenous nerve entrapment in the medium third of the thigh (case 1). The saphenous nerve (1) which was displaced is squeezed in the space (2) between the fibrous band of adductor magnus muscle (3) raised by a lace (4) and the vastus medialis muscle (5). (6) = sartorius muscle dissected. stimulation of the proximal trunk of the $\mathrm{SN}$ just below the inguinal ligament (fig 1), and were almost normal after left IPB stimulation. Nevertheless, in 2 of 6 recordings, P1 was absent. After left PDB stimulation, the P1 amplitude was lower than normal. Moreover, in 3 of 5 recordings, P1 was absent. After left TDB stimulation, the cortical SEP differed from that of the normal side (table 3 ). It may be concluded that there were abnormalities of the SEP from the two last branches. These data together with the observed abolition of SNAP (table 1) support the diagnosis of SN entrapment in the left femoral canal.

Neurolysis was performed in 1989 ( $P r$ Sedel) and this operation agreed with the electrophysiological abnormalities. The SN was compressed in the medium third of the left thigh between the vastus medialis muscle below and a half-centimetre diameter fibrous band of the adductor magnus muscle above (fig 2). The consequences of this operation were favourable, with resolution of previous pain.

CASE 2

It can be seen from fig $3 a$ and table 3 that there was complete abolition of the cortical responses on the right side. Treatment by 3 local infiltrations of corticosteroid (CTS) combined with rest, physiotherapy and oral nonsteroidal anti-inflammatory drugs (NSAIDs) brought about progressive improvement. Six months after the first SEP, the second SEP showed a complete recovery of cortical responses (fig $3 b$ ).

CASE 3

The first SEP after stimulation of the right IPB of the SN differed slightly from that of the left. The SEP from the other branches of the SN were identical for two sides (table 3). Because of the normal SN'SCV in the leg and the normal SEP of the other branches of the $\mathrm{SN}$, this suggested infrapatellar nerve entrapment. Two local infiltrations of CTS and oral NSAIDs were given for 15 days. Three months later, there was improvement of amplitude and latency of SEP after right IPB stimulation: the amplitude ratio was then $0 \cdot 84$.

CASE 4

There was evident asymmetry of cortical responses after stimulation of IPB, PDB and TDB of the left SN compared with the right side (table 3). 

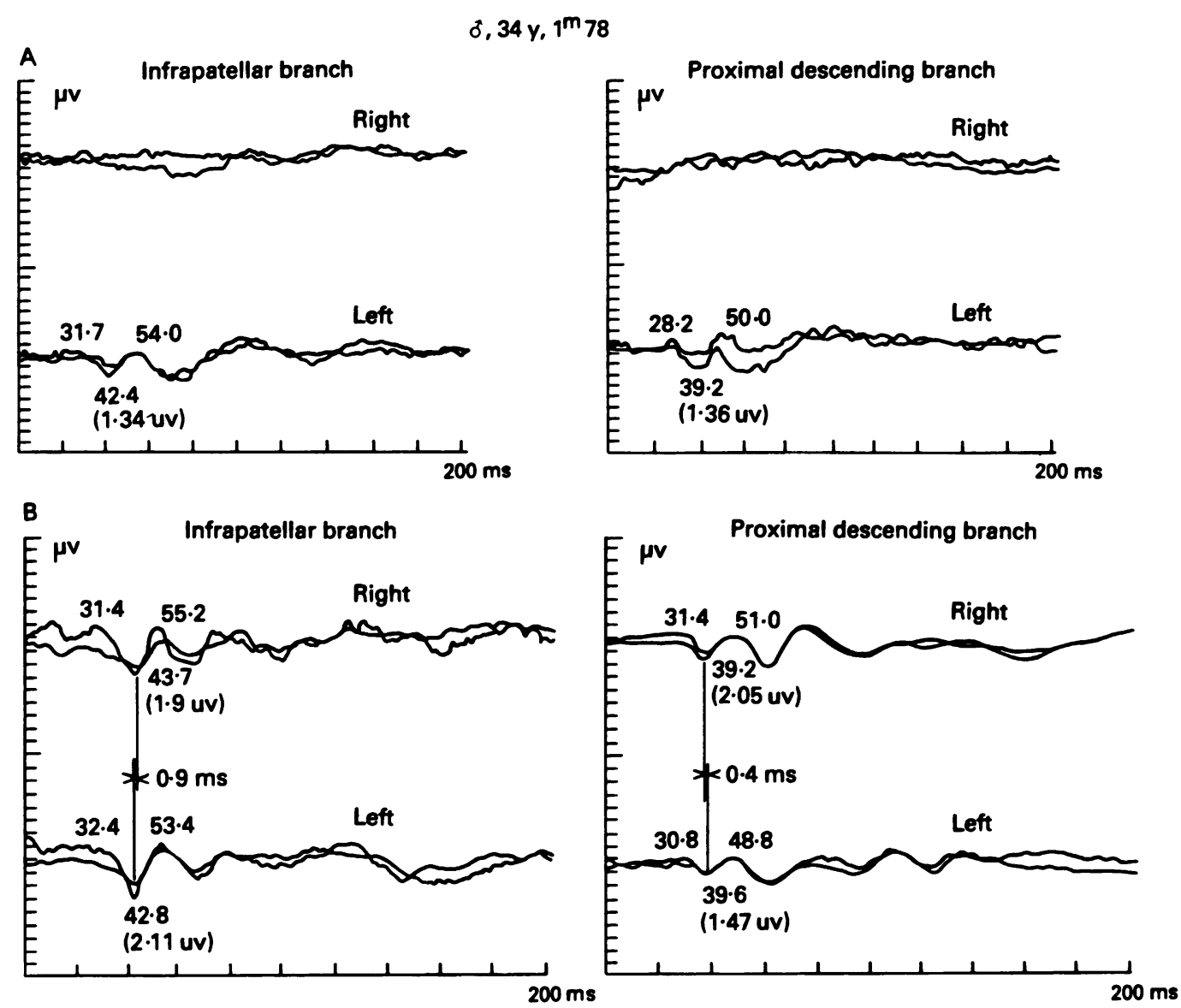

Figure 3 SEP after stimulation of the two branches of the saphenous nerve (case 2). Upper trace $=$ right affected side. Lower trace = left normal side. (a) before treatment; (b) after treatment.

\section{Discussion}

A cortical SEP can easily be elicited from the $\mathrm{SN}$ in normal subjects and patients, in those with serious peripheral nerve lesions and its corresponding SNAP is abolished. This results from reorganisation and central amplification of incoming peripheral volleys by activation of few peripheral fibres. ${ }^{7}$ This abolition of SNAP could suggest a conduction block in the affected side. The most frequent abnormalities were the prolongation of latency in all patients, in one of whom it was the only abnormality (case 4), while reduced amplitude was evident in 3 cases (cases 1,2,3), with unilateral absence in case 2 .

In case 1 , the absence of any latency change of the SEP after stimulation of the IPB and PDB was probably related to the "diluting" effect by a large length of normally conducting peripheral and central nerve fibres of the short segment of these fibres with slowed conduction. Although the amplitude is too variable to be meaningful in absolute terms, an excellent index is the ratio of the smallest amplitude on the injured side/largest on the normal side. This indicates significant conduction block or axonal loss, or both. ${ }^{7}$ This observation is unique in the literature by virtue of its topography and mode of compression. The absence of recordable cortical SEP after stimulation of the affected side in case 2 suggests maximal conduction block and its complete recovery six months later probably indicates neurapraxia by transient compression. The anti-inflammatory effect of CTS decreases oedema and compression of nerves. ${ }^{5}$ In case 3 , one abnormality was seen in the SEP after right IPB stimulation. This may be due to the true infrapatellar entrapment caused by stretching of the $\mathrm{SN}$ when it leaves the aponeurotic sheath of the femoral canal. It may be aggravated by strong hyperextension of the knee and hip. Traction may cause inflammation, oedema and paraesthesia. ${ }^{5}$ Pain may be secondary to spontaneous firing of the SN after compression. ${ }^{14}$ If the nerve compression is transient, local anaesthetic may stop the pain cycle, because it interferes with the activation of ectopic foci and diminishes spontaneous firing and paraesthesia. ${ }^{14}$ But in chronic compression, inflammation and fibrosis may involve the nerve. This may explain the effectiveness of CTS on the nerve oedema, compression and on paraesthesia. These two cases are similar to Dumitru and Windsor's report ${ }^{4}$ and can be observed in sportsmen. In case 4, there was a suggestion of "scar entrapment neuropathy" following meniscectomy several years previously. A neuroma was characterised essentially by an abnormality of the latency of SEP probably due to intense local demyelination in the SN. This case agrees with those reported by Kopell, Thompson and Worth, et al. A past meniscectomy in two patients of the first author was not mentioned in 1960, but only in the report of $1976 .{ }^{3}$ So we consider that these two interesting cases do not exactly correspond to primary entrapment. In 10 of 15 cases reported by the second authors, the disease was the 
consequence of a meniscectomy. ${ }^{2}$ It is essential for the physician to consider SN entrapment when the more common causes of gonalgia have been excluded.

The authors are grateful to Dr D Marsch for help with editing and Dr Bathien for his advice and Professor Sedel for figure 2 .

First presented at the Fourth International Evoked Potentials Symposium, September 30th-October 3rd, 1990, Toronto

1 Mozes MM, Ouaknine G, Nathan H. Saphenous nervous entrapment simulating vascular disorder. Surgery 1975 77:299-303

2 Worth RM, Kettelkamp DB, Defalque RJ, Duane KU. Saphenous nerve entrapment. Am $f$ Sports Med 1984; 12:80-81

3 Kopell HL, Thompson WAA. Peripheral entrapment neuropathies. New York: RE Krieger, 1976:52-56.

4 Dumitru D, Windsor RE. Subsartorial entrapment of the saphenous nerve of a competitive female bodybuilder. Phys Sports Med 1989;17:116-25.

5 Romanoff ME, Cory Ph. C, Kalenak A, Deyser GC, Marschall WK. Saphenous nerve entrapment adductor canal. Am $\mathcal{F}$ of Sports Med 1989;17 (4): 478-81.
6 Tranier S, Durey A, Sedel L, Liot F. Potentiel évoqué somesthésique et son intérêt dans un syndrome canalaire particulier du nerf saphène interne. A propos d'un cas. particulier du nerf saphène in
Neurophysiol Clin 1989;19:517.

7 Eisen A Elieker G Sensory nerve stimulation and evoked cerebral potential. Neurol 1980;30:1097-1105

8 Vogel P, Vogel H. Somatosensory cortical potentials evoked by stimulation of leg nerves: analysis of normal values and variability; diagnostic significance. $\mathcal{F}$ Neurol 1982;228: 97-111.

9 Synek VM, Cowan JC. Saphenous nerve evoked potential and the assessment of the intraabdominal lesions of the femoral nerve. Muscle Nerve 1983;6:453-6.

10 Arthornthurasook A, Gaem-Im K. Study of the infrapatellar nerve. Am $\mathcal{F}$ of Sports Med 1988;16:57-9.

11 Arthornthurasook A, Gaem-Im K. The sartorial nerve: its relationship to the medial aspect of the knee. Am $\mathcal{f}$ of Sports Med 1990;18:41-2.

12 Wainapel SF, Kim DJ, Edel A. Conduction studies of the saphenous nerve in healthy subjects. Arch Phys Med Rehabil 1978;59:316-

13 Guiheneuc $P$. The use of monosynaptic reflex responses in man for assessing the different types of peripheral neuropathies. Desmedt JE, ed. Motor control mechanism in health and disease. New York: Raven Press, 1983: 924-49.

14 Ochoa JL, Toresbjork HE. Paresthesiae from ectopic impulse generation in human sensory nerves. Brain 1980 103:853-5. 